\title{
Visualisasi Gedung Sekolah 3D dengan Konsep Virtual Reality Berbasis Android
}

\author{
Danang Dewantoro*, Septi Andryana, Aris Gunaryati \\ Fakultas Teknologi Komunikasi dan Informatika, Informatika, Universitas Nasional, Jakarta, Indonesia \\ Email: 1*danangdewant@gmail.com, ${ }^{2}$ septi.andryana@civitas.unas.ac.id, ${ }^{3}$ aris.gunaryati@civitas.unas.ac.id \\ ${ }^{*)}$ Email Korespondensi: danangdewant@gmail.com
}

\begin{abstract}
Abstrak-Promosi dan pengenalan gedung sekolah pada dasarnya masih menggunakan media seperti brosur atau pamflet, sebab itu diperlukan perangkat lunak yang dapat mengenalkan dan memberikan informasi mengenai gedung sekolah spesifiknya di SMK 25 Jakarta. Penelitian ini bertujuan untuk memberikan pengenalan gedung SMK Negeri 25 Jakarta berbasis Virtual Reality menggunakan alat VR Box sebagai media informasi mengenai ruangan-ruangan kepada calon murid baru. Aplikasi ini memanfaatkan metode research and development (R\&D) dengan model ADDIE, model ini berfungsi guna melaksanakan penilaian secara berkala dalam setiap fase sehingga produk yang dihasilkan menjadi valid. Hasil pengujian validasi menyimpulkan bahwa sistem valid. Pengujian tingkat kepuasan pengguna setelah menggunakan aplikasi Virtual Reality SMKN 25 Jakarta dapat disimpulkan bahwa rata-rata pengguna memberikan nilai 3.4 atau cukup pada kepuasan tampilan menu aplikasi, dan memberikan nilai 3.05 pada kepuasan mode virtual.
\end{abstract}

Kata Kunci: Virtual Reality, Gedung Sekolah, Android

\begin{abstract}
Promotion and introduction of school buildings still uses media such as brochures or pamphlets, because it requires software that can introduce and provide information about specific school buildings in SMK 25 Jakarta. This study aims to provide an introduction to the Virtual Reality 25 Jakarta Vocational High School building using the VR Box as a medium of information about the rooms to prospective new students. This application utilizes the method of research and development (R\&D) with the ADDIE model, this model serves to carry out periodic assessments in each phase so that the resulting product becomes valid. The validation test results concluded that the system is valid. Testing the level of user satisfaction after using the Virtual Reality application SMKN 25 Jakarta can be concluded that the average user gives a value of 3.4 or enough on the satisfaction of the application menu display, and gives a value of 3.05 on the satisfaction of virtual mode.
\end{abstract}

Keywords: Virtual Reality, School Buildings, Android

\section{PENDAHULUAN}

Pada saat masa penerimaan murid baru biasanya sekolah memberikan sebuah brosur atau flayer yang berguna untuk mempromosikan sekolah tersebut sehingga terdapat biaya yang tidak sedikit dikeluarkan untuk membuat brosur tersebut [1]. Aplikasi virtual bisa menjadi salah satu solusi yang dapat dijadikan alternatif untuk permasalahan tersebut. Aplikasi ini akan menampilkan kondisi dari gedung Sekolah Menengah Kejuruan Negeri 25 Jakarta, sehingga aplikasi ini akan memberikan informasi seputar kondisi dari tempat atau sekolah tersebut. Aplikasi ini akan mempermudah untuk lebih mengenal dan megetahui Sekolah Menengah Kejuruan Negeri 25 Jakarta, dengan media berbasis 3 dimensi yang dapat di install pada Smartphone yang saat ini sudah banyak mendukung aplikasi virtual reality. sehingga akan memberikan kemudahan dan kesan menarik untuk dilihat karena disajikan dalam bentuk virtual yang terlihat nyata seperti kondisi pada aslinya.

Dalam membangun aplikasi ini diperlukan adanya batasan agar tidak menyimpang dari apa yang direncanakan berikut merupakan batasan masalahnya:

1) Visualisasi 3D hanya dilakukan pada lingkungan SMKN 25 Jakarta, aplikasi ini hanya berbasis android.

2) Virtual Reality Glasses atau kacamata virtual reality sebagai alat bantu penggunaan aplikasi.

3) Aplikasi ini dibangun menggunakan software pendukung Unity 3D dan Sweet Home 3D.

Adapun tujuan dari pembuatan aplikasi ini adalah Menghasilkan visualisasi gedung sekolah 3D di SMKN 25 Jakarta Aplikasi Virtual Reality telah dikembangkan pada beberapa penelitian untuk media pembanding, pada jurnal pertama menguraikan tentang aplikasi Virtual Reality Gedung Teknologi Informasi yang berada di Politeknik Negeri Padang menggunakan rancangan virtual reality yang bertujuan sebagai media penyampaian informasi kampus [2]. Pada jurnal kedua membahas tentang media pengenalan informasi mengenai universitas Politeknik Negri Indramayu berbasis ponsel android dengan menggunakan konsep virtual reality [3]. Pada jurnal ketiga menjelaskan tekonolgi virtual reality sebagai media informasi kampus. Pada jurnal keempat membahas aplikasi virtual reality yang berada di Museum Sunan Drajat Lamongan selaku media pembelajaran sejarah [4]. Pada jurnal ke lima yaitu selaku media penunjang promosi Gedung di Rektorat Universitas Udayana berbasis virtual reality dengan memiliki fitur deskripsi berupa teks mengenai ruangan dan disertai dengan suara [5].

\section{METODE PENELITIAN}

\subsection{Perancangan Research and Development (R \& D)}

Pengkajian ini menggunakan jenis Penelitian Pengembangan alias Research and Development (R \& D) yakni proses pengkajian yang digunakan untuk menghasilkan produk tertentu, dan menguji kefektifan produk 
tersebut[6]. Model yang digunakan dalam penelitian pengembangan ini adalah model ADDIE. Model ADDIE merupakan kependekan kata dari lima tahapan pada model ADDIE itu sendiri antara lain analisis, desain, development, implementasi, dan evaluasi [7]. Berikut tahapan dalam model ADDIE.

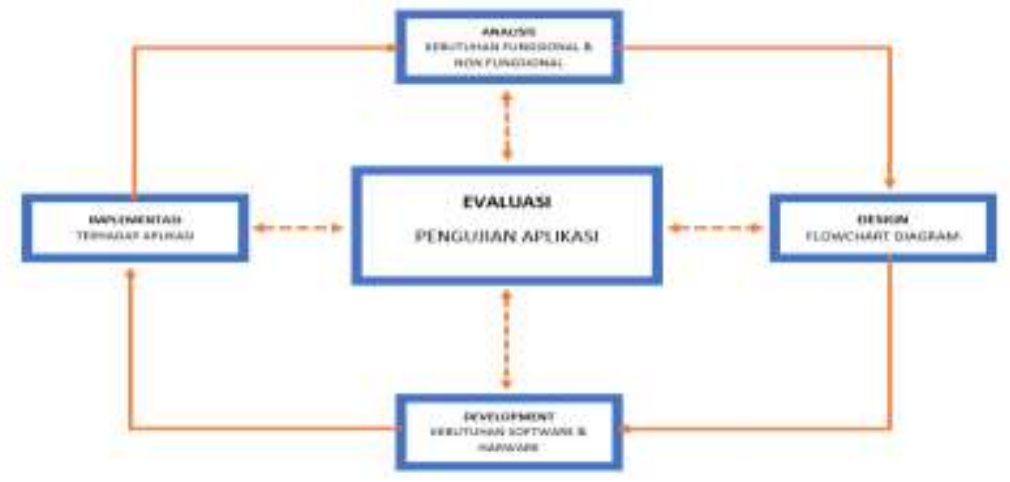

\subsubsection{Analisis}

Gambar 1. Tahapan dalam model ADDIE

Tahap analisis yaitu mengidentifikasi menngenai probelmatika yang kedapatan maka dapat dijadikan referensi di dalam memajukan apliaksi.

1) Kebutuhan Fungsional

Berdasarkan analisis pada pengembangan aplikasi Virtual Reality Pengenalan Gedung SMK Negeri 25 Jakara, didapatkan kebutuhan fungsional sebagai berikut:

a. Aplikasi mampu menampilkan visualisasi gedung SMKN 25 Jakarta berbasis 3D.

b. Aplikasi mampu memainkan suara serta menampilkan informasi mengenai ruangan-ruangan sekolah.

c. Aplikasi dapat dilihat dalam mode virtual reality 3D.

2) Kebutuhan Non Fungsional.

Berlandaskan uraian pada pengembangan aplikasi Virtual Reality, terdapat sejulah kebutuhan non fungsional yang dibutuhkan:

a. Aplikasi ini mampu dijalankan pada operasi Android paling tidak versi 4.4 (KitKat) dan memiliki sensor gyroscope.

b. Aplikasi memiliki tampilan yang user friendly, orientasinya agar pengguna tertarik dan kiranya dapat menggunakan aplikasi tersebut.

c. Aplikasi dapat mengikuti pergerakan smartphone.

\subsubsection{Desain}

1) Flowchart Diagram activity

Flowchart diagram merupakan runtut aktivitas dalam sistem yang sedang dipersiapkan, dengan cara tiap-tiap alur bermula, keputusan yang berpotensi terjadi, dan bagaimana mereka berkesudahan [8]. Adapun flowchart diagram aplikasi virtual reality SMKN 25 Jakarta.

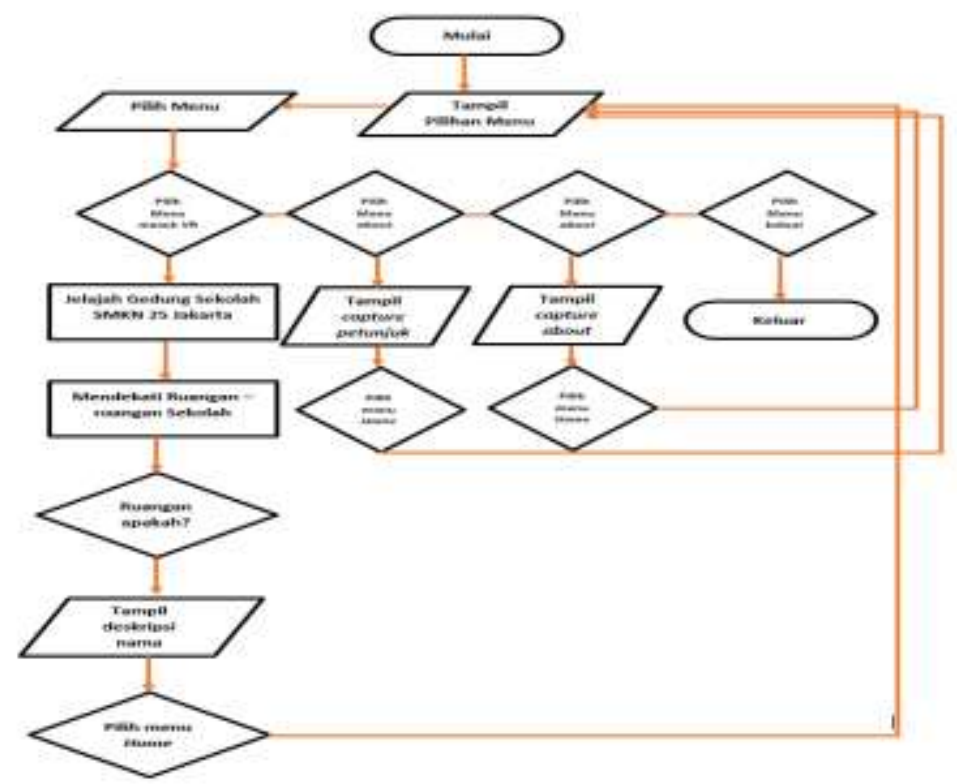

Gambar 2. Flowchart Diagram virtual reality SMKN 25 Jakarta. 


\subsubsection{Development}

Pada tahapan pengembangan, konsep yang sudah pernah dibuat sebelumnya di implementasikan dengan perangkat yang sudah sesuai. Mula-mula dilakukan penciptaan objek 3D dengan tahapan modelling, texturing, dan lighting sesuai dengan yang direncanakan pada fase pra pembuatan aplikasi [9]. Selanjutnya yang dibutuhkan baik perangkat lunak maupun perangkat keras.

1) Kebutuhan Perangkat Lunak

Kebutuhan Perangkat Lunak berlandaskan pengkajian kebutuhan yang dilandaskan, adapun perangkat lunak yang dilandaskan dalam peningkatan aplikasi Virtual Reality SMKN 25 Jakarta adalah sebagai berikut:

a. Unity 2017.4.34f1 (64-bit) di perlukan selaku penyunting dalam mengembangkan Aplikasi Virtual Reality.

b. SweetHome 3D di perlukan untuk membentuk Objek gedung sekolah 3D.

c. Cardboard SDK atau Library SDK di perlukan demi menciptakan aplikasi Virtual Reality.

d. SDK GoogleVRForUnity di perlukan guna memperlihatkan mode VR pada smartphone

e. Clideo digunakan untuk mengedit audio.

2) Kebutuhan Perangkat Keras

Aplikasi Virtual Reality Pengenalan gedung SMKN 25 Jakarta dikembangkan menggunakan perangkat keras laptop dan smartphone sebagai berikut:

a. Perangkat Komputer

Laptop MSI GL62 7QF

Processor Intel@ Core ${ }^{\mathrm{TM}}$ i7-7700 HQ @ 2.80GHz (8 CPUs), $2.8 \mathrm{GHz}$

RAM 12 GB

HDD 1TB dan SSD $120 \mathrm{~GB}$

VGA GeForce GTX 960M

b. Perangkat Smartphone

Smartphone Nokia 6.1 Plus

CPU Octa-core Chipset Qualcomm Snapdargon 636

GPU Adreno 509

Resolusi pixel 1080 x 2280, rasio layar19:9

RAM 6 GB dan Memory internal 32 GB

\subsubsection{Implementasi}

Pada bagian ini pengamat berkenan perihal penerapan aplikasi SMKN 25 Jakarta. Adapun tahapan implementasi aplikasi.

Tabel 1. Tahapan implementasi aplikasi

\begin{tabular}{cc}
\hline No. & \multicolumn{1}{c}{ Implementasi } \\
\hline 1. & Peneliti memperkenalkan aplikasi Virtual Reality SMKN 25 Jakarta kepada siswa siswi. \\
2. & $\begin{array}{l}\text { Peneliti menjelaskan tata cara penggunaan aplikasi Virtual Reality SMKN 25 Jakarta } \\
\text { mulai dari membuka aplikasi, memilih menu pada aplikasi, pemasangan smartphone } \\
\text { pada VR BOX, melakukan penjelajahan dan cara menekan button informasi. }\end{array}$ \\
\hline
\end{tabular}

\subsubsection{Evaluasi}

Pada bagian menjelaskan ulasan mengenai Jenis pengujian yang akan digunakan seperti Uji Respon Pengguna dan Uji penilaian tampilan menu aplikasi. Maksud tentang pengujian apliaksi ialah guna mendapati kelemahan atau kelayakan aplikasi, maka aplikasi bisa disempurnakan demi meminimalisir kesalahan yang terjadi sebelum diimplementasikan ke publik [10].

\section{HASIL DAN PEMBAHASAN}

Hasil yang sudah tercapai di dalam pembuatan aplikasi visualisasi bangunan sekolah diantaranya adalah.

\subsection{Pemodelan Gedung}

Dalam melangsungkan rancangan desain bangunan dan ruangan, sebagai subjek studi kasus menerapkan gedung Sekolah Menengah Kejuruan Negeri 25 yang berlokasi di Jakarta Selatan, gedung dengan 4 lantai ini memiliki beberapa raungan. Pada tahap perancagan desain gedung dan ruangan dibuat menggunakan hasil foto observasi [11]. Tahap pembuatan model 3D gedung sekolah seperti pintu, jendela, dan objek 3D yang lainnya menggunakan software Sweet Home 3D.Pada software Sweet Home 3D yang pertama kali adalah membuat model gedung sekolah menengah kejuruan negeri 25 Jakarta sesuai dengan bentuk orisinilnya agar model 3D yang dibuat terlihat seperti realistis. 


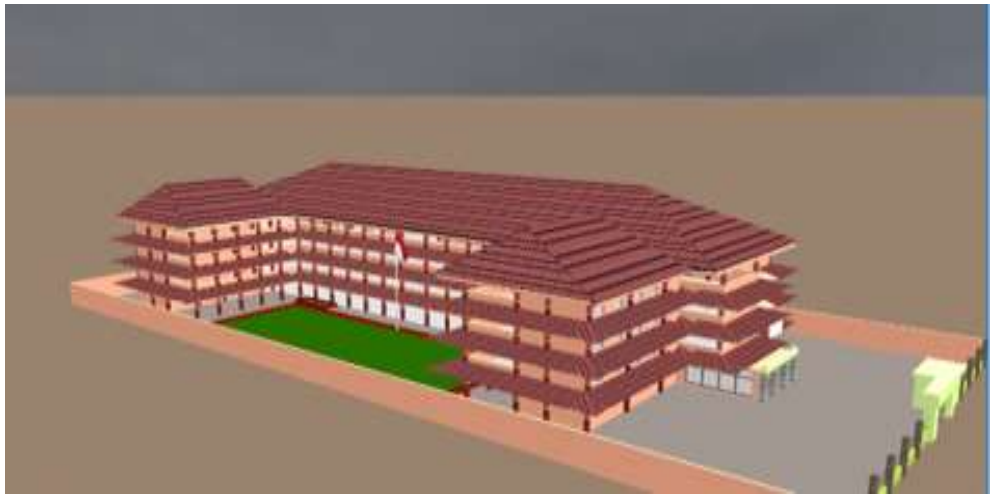

Gambar 3. Pemodelan Gedung SMKN 25 Jakarta

\subsection{Pergerakan Kamera dan Perjalanan}

Pergerakan kamera dan perjalanan merupakan fitur mendasar yang berjalin langsung dengan proses eksplorasi gedung sekolah. User dapat melangkah maju dengan teknik sedikit merundukan kepala dan untuk berhenti berjalan dengan mengangkat kepala. Dengan teknik ini User tidak memerlukan button controller agar bisa berjalan pada saat eksplorasi pada saat mode VR [12]. Aksi berjalan yaitu dengan membaca angle kamera dengan dukungan sensor Gyroscope pada perangkat Smartphone android.

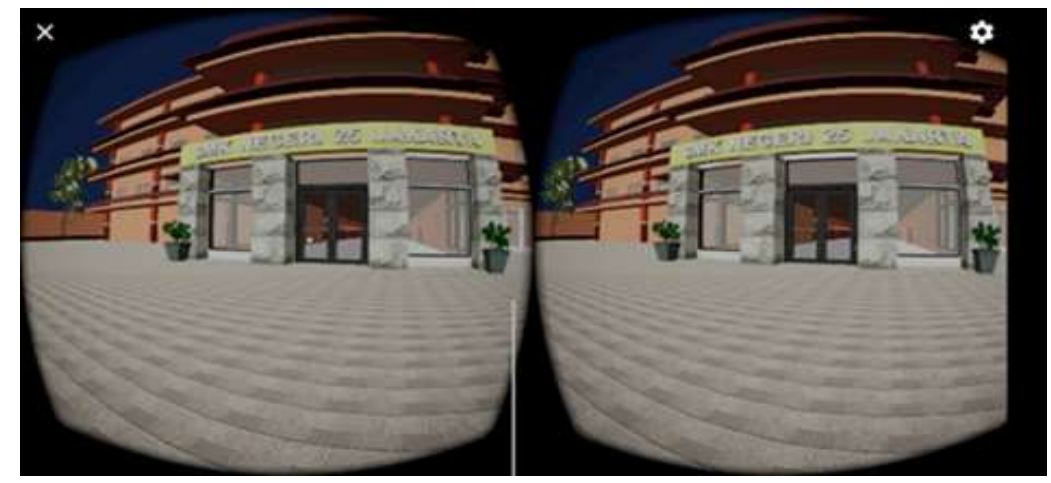

Gambar 4. Tampilan view kamera pada mode VR

\subsection{Perancangan Interface}

Pertimbangan tampilan antarmuka pada $V R$ yang mendasar pada ponsel android diperoleh empat menu. Menu tersebut terdiri dari masuk VR, Petunjuk Penggunaan, about, dan Keluar [13]. Ketika User menekan button masuk $V R$ maka akan masuk kedalam mode Virtual Reality yang dimana user dapat menjelajah keseluruhan gedung SMKN 25 Jakarta. Pada button petunjuk penggunaan user dapat memahami aturan pemakaian yang berisi prosedur penggunaan aplikasi, sedangkan button about berisi perihal aplikasi VR itu sendiri dan perihal pembuat aplikasi VR [14]. Apabila hendak mengakhiri aplikasi pengguna pilih button keluar pada tampilan mainmenu aplikasi VR.

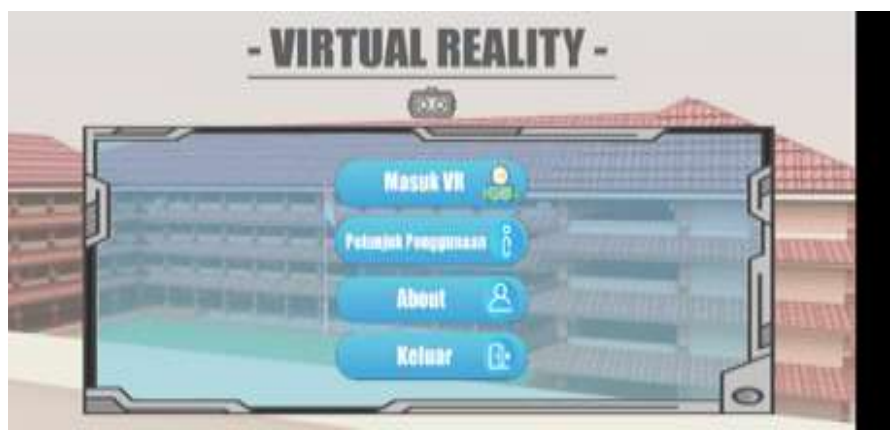

Gambar 5. Tampilan Mainmenu pada aplikasi

\section{a. Halaman Mainmenu}

Selepas menjalankan aplikasi, tahap mula-mula yakni menampilkan halaman mainmenu. Diperoleh sejumlah menu aplikasi yang dapat di akses bagi pemakai aplikasi. 


\section{b. Halaman Menu Masuk VR}

Pada halaman ini user diarahkan masuk ketampilan mode Virtual Reality dan dihalaman ini user dapat melakukan perjalanan pada lingkungan gedung sekolah [15].

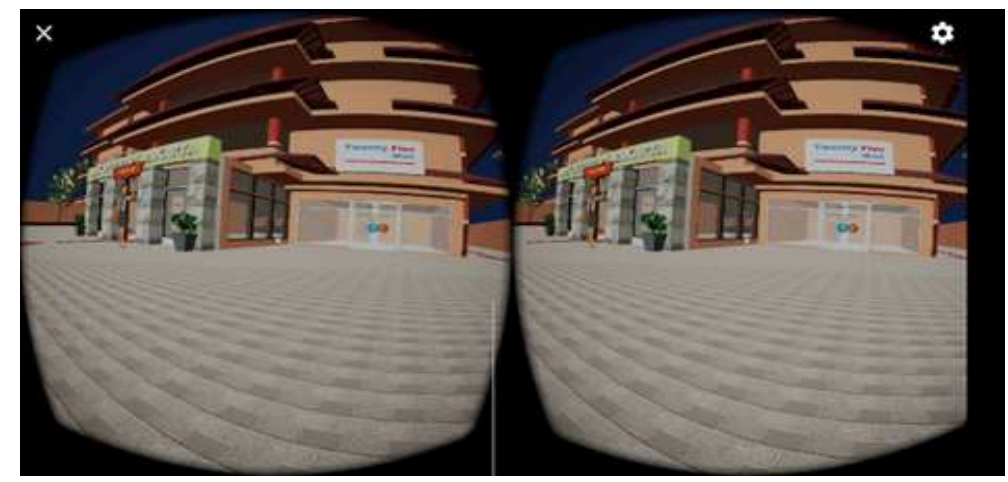

Gambar 6. Tampilan mode masuk $V R$

\section{c. Halaman Menu Petunjuk Penggunaan}

Pada tampilan petunjuk penggunaan di gunakan guna menyampaikan petunjuk mengenai aturan penggunaan aplikasi Virtual Reality pada user, sehingga user dapat langsung mengetahui cara pemakaian dan mengaplikasikannya [16]. Tampilan petunjuk penggunaan dapat dilihat pada gambar 7.

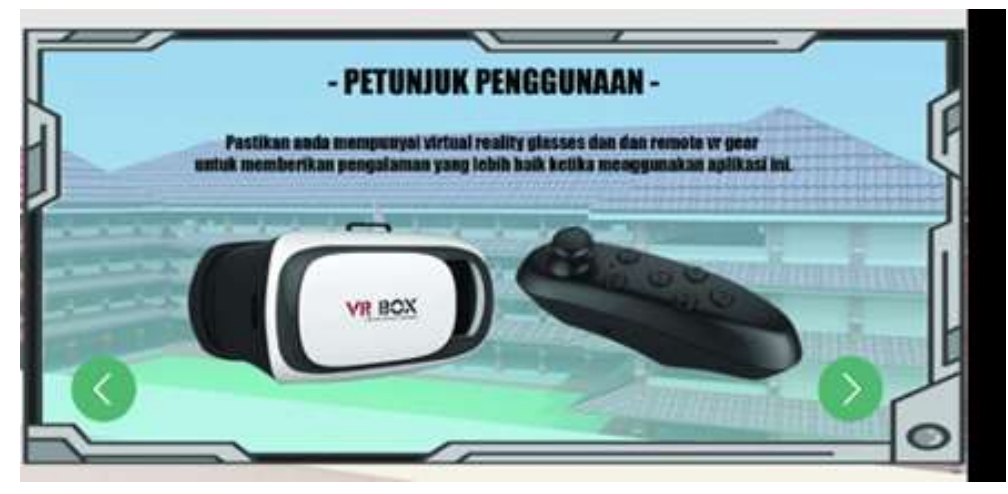

Gambar 7. Tampilan Petunjuk Penggunaan Aplikasi VR

\section{d. Halaman Menu About}

Pada tampilan menu About ini digunakan untuk mengetahui perihal pembuat aplikasi Virtual Reality dan tentang alasan aplikasi ini dibuat [17].

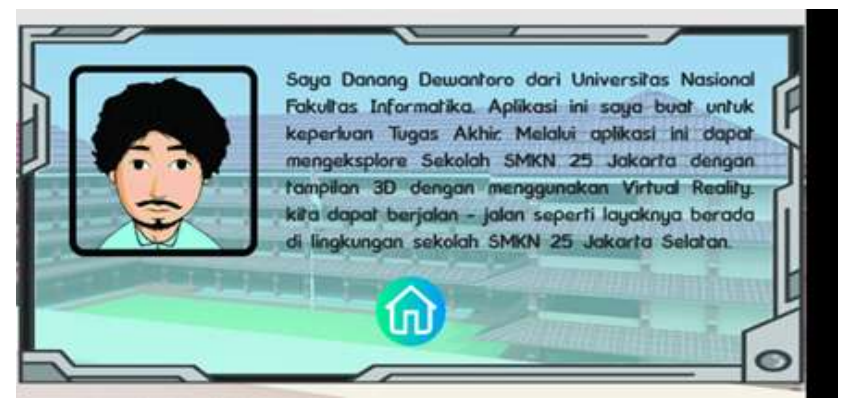

Gambar 8. Tampilan Menu about Aplikasi VR

\section{e. Halaman Menu Keluar}

Dihalaman ini terdapat button keluar yang digunakan untuk keluar dari aplikasi apabila user menekan buutton.

\subsection{Media Informasi Ruang Gedung Sekolah}

Informasi mengenai ruangan untuk mengetahui nama dari ruangan berupa text dan suara yang merupakan konten informasi untuk aplikasi VR dibuat dengan menggunakan bantuan Script C\# untuk memainkan Scene, yang 
Available Online at https://ejurnal.stmik-budidarma.ac.id/index.php/mib DOI $10.30865 /$ mib.v4i1.1866

dimana didalam script terdapat alur untuk menghubungkan antar scene [18] [19]. Script dihubungkan ke sebuah button yang apabila button terssebut di klik maka akan menampilkan nama dari ruangan tersebut.

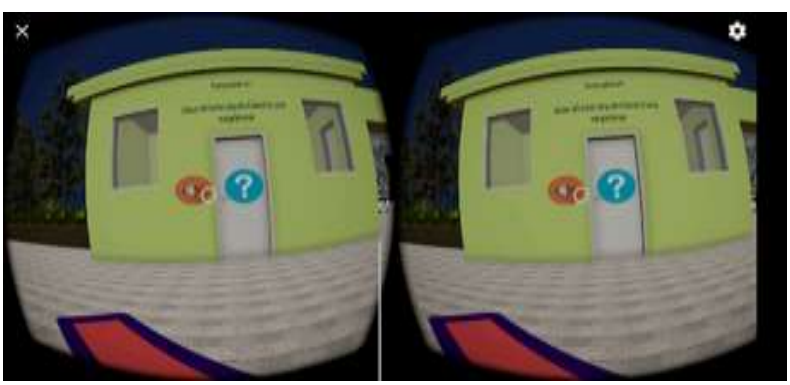

Gambar 9. Tampilan Informasi Mengenai Nama ruangan berupa text dan suara

\subsection{Pengujian Aplikasi}

Tabel 2. Uji Coba Aplikasi Virtual Reality pada perangkat smartphone android

\begin{tabular}{|c|c|c|c|c|}
\hline No. & Perangkat & Spesifikasi & Uji Coba & Hasil \\
\hline 1. & Nokia 6.1 Plus & $\begin{array}{l}\text { Snapdragon } 636 \text { Octa-core } 1.8 \\
\text { GHz Kryo 260, 5,8 inci, } 1080 \text { x } \\
2280 \text { pixels, dan RAM } 6 \text { GB. }\end{array}$ & & Baik \\
\hline 2. & Redmi Note 5 & $\begin{array}{l}\text { Snapdragon } 636 \text { Octa-Core } 1,8 \\
\text { GHz Kryo 260, 5.99 inci } 1080 \text { x } \\
2160 \text { pixels, dan RAM } 4 \text { GB. }\end{array}$ & & Baik \\
\hline 3. & Xiaomi MI A1 & $\begin{array}{l}\text { Snapdragon } 625, \quad \text { octa-core } \\
\text { Cortex-A53 } 2 \mathrm{GHz}, 5,5 \text { inci, } 1.920 \\
\text { x } 1.080 \text { pixels, dan RAM } 4 \text { GB }\end{array}$ & & Baik \\
\hline 4. & $\begin{array}{c}\text { Xiaomi MI } 8 \\
\text { Lite }\end{array}$ & $\begin{array}{l}\text { Qualcomm Snapdragon } 660,6.26 \\
\text { inci, } 1080 \times 2280 \text { pixels, dan RAM } \\
\text { 4GB }\end{array}$ & & Baik \\
\hline
\end{tabular}

\section{a. Uji coba kelayakan aplikasi pada smartphone}

Pengujian aplikasi dilakukan memanfaatkan perangkat smartphone android guna mengaplikasikan aplikasi Visualisai Gedung SMKN 25 Jakarta menggunakan konsep Virtual Reality. Pengujian aplikasi Virtual Reality yang berlangsung bertujuan untuk mendeteksi performa dan kapasitas dari aplikasi menggunakan perangkat dengan rincian spesifikasi yang di sebutkan pada tabel 2. Dengan perangkat smartphone yang memiliki sensor Gyroscope, perolehan yang didapat adalah aplikasi VR berjalan lumayan lancar di seluruh smartphone yang di ujikan, walaupun masih sedikit lama untuk masuk ke dalam mode VR. Aplikasi membutuhkan perangkat setidaknya dengan RAM 4GB agar dapat menjalankan aplikasi dengan lancar.

Tabel 3. Pengujian Kecepatan Aplikasi pada Smartphone

\begin{tabular}{ccccc}
\hline Pergantian Scene & $\begin{array}{c}\text { Smartphone } \\
\mathbf{1}\end{array}$ & $\begin{array}{c}\text { Smartphone } \\
\mathbf{2}\end{array}$ & $\begin{array}{c}\text { Smartphone } \\
\mathbf{3}\end{array}$ & $\begin{array}{c}\text { Smartphone } \\
\mathbf{4}\end{array}$ \\
\hline & & & & \\
& 4 Detik & 4 Detik & 4 Detik & 4 Detik \\
\hline
\end{tabular}




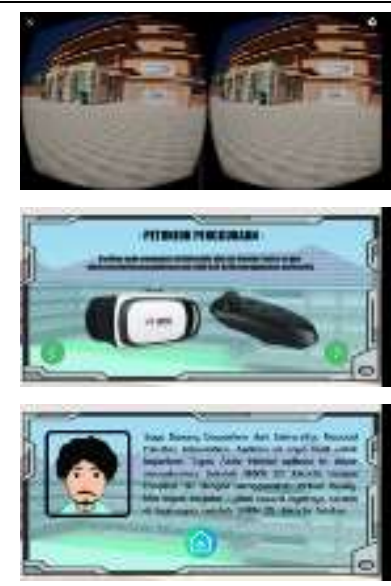

23 Detik 25 Detik 24 Detik

1,30 Detik 2 Detik 1,38 Detik 1,30 Detik

\section{1,35 Detik 1,38 Detik 1,36 Detik 1,36 Detik}

\section{b. Pengujian tingkat kecepatan aplikasi pada smartphone}

Pegujian ini dilakukan untuk mengukur tingkat kecepatan aplikasi pada berbagai scene dengan menggunakan smartphone yang berbeda.

Tabel 4. Pengujian Black box

\begin{tabular}{|c|c|c|c|c|}
\hline \multirow{2}{*}{ No. } & \multirow{2}{*}{ Fungsi Yang di Uji } & \multicolumn{2}{|c|}{ Hasil } & \multirow{2}{*}{ Keterangan } \\
\hline & & Berhasil & Gagal & \\
\hline 1. & Button Masuk VR & $\checkmark$ & & Valid \\
\hline 2. & Button Info ruangan & $\checkmark$ & & Valid \\
\hline 3. & Button Suara & $\checkmark$ & & Valid \\
\hline 4. & Button Home & $\checkmark$ & & Valid \\
\hline 5. & Button Petunjuk Penggunaan & $\checkmark$ & & Valid \\
\hline 6. & Button About & $\checkmark$ & & Valid \\
\hline 7. & Button Keluar & $\checkmark$ & & Valid \\
\hline
\end{tabular}

\section{c. Pengujian Black Box}

Fase ini pengujian dilandaskan berdasarkan hasil yang sudah dilakukan. Semua menu dan button berfungsi dan berjalan 100\% dengan keterangan valid sebanding dengan yang diinginkan.

Tabel 5. Kuesioner

\begin{tabular}{clc}
\hline No. & \multicolumn{1}{c}{ Parameter } & $\begin{array}{c}\text { Skala Nilai } \\
(\mathbf{1 - 5})\end{array}$ \\
\hline 1. & Apakah anda mengetahui SMKN 25 Jakarta \\
2. & Tampilan menu aplikasi virtual reality SMKN 25 Jakarta \\
3. & Apakah aplikasi nyaman untuk digunakan \\
\hline \multicolumn{2}{c}{ Tingkat kepuasan skenario Virtual Reality SMKN 25 Jakarta } \\
\hline 4. & Apakah anda merasa kesulitan \\
5. & Apakah aplikasi ini terasa nyata \\
6. & Apakah anda merasa terhibur \\
7. & Apakah informasi yang diberikan membantu anda \\
\hline
\end{tabular}

\section{d. Parameter Pengujian}

Pada fase ini mengulas mengenai pengujian dan evaluasi pada aplikasi yang dikembangkan. Percobaan yang dilakukan adalah pengujian terhadap kebutuhan fungsionalitas dan manfaat sistem [20]. Pengujian fungsionalitas mengacu kepada persoalan penggunaan sedangkan pengujian kegunaan program dilakukan dengan mengetahui persepsi dari pengguna terhadap aplikasi sistem. Hasil evaluasi menguraikan mengenai rangkuman hasil pengujian pada bagian kesudahan bab ini.

Tabel 6. Hasil Kuesioner

\begin{tabular}{clc}
\hline No. & \multicolumn{1}{c}{ Parameter } & $\begin{array}{c}\text { Skala Nilai } \\
(\mathbf{1 - 5})\end{array}$ \\
\hline 1. & Apakah anda mengetahui SMKN 25 Jakarta & Ya/tidak \\
2. & Tampilan menu aplikasi virtual reality SMKN 25 Jakarta & 43433 \\
\hline
\end{tabular}




\begin{tabular}{clc}
\hline 3. & Apakah aplikasi nyaman untuk digunakan & 33334 \\
\hline \multicolumn{3}{c}{ Tingkat kepuasan skenario Virtual Reality SMKN 25 Jakarta } \\
\hline 4. & Apakah anda merasa kesulitan & 32232 \\
5. & Apakah aplikasi ini terasa nyata & 33443 \\
6. & Apakah anda merasa terhibur & 33333 \\
7. & Apakah informasi yang diberikan membantu anda & 33433 \\
\hline
\end{tabular}

\section{e. Hasil Kuesioner}

Pengisian kuesioner melibatkan 5 orang pelajar sekolah SMKN 25 Jakarta. Pengisi kuesioner terdiri dari 3 lelaki dan 2 wanita. Pengguna melakukan pengujian terhadap aplikasi sesuai atas poin penilaian pada kuesioner. Setiap poin penilaian memiliki skala nilai 1 sampai 5, atas keterangan 1 amat buruk, 2 buruk, 3 cukup, 4 baik, 5 amat baik.

Tabel 7. Hasil Perolehan Kuesioner

\begin{tabular}{|c|c|c|c|c|c|}
\hline No. & Nama & Objek & Skor & Rata - rata & Hasil \\
\hline 1. & Meutia Nur Anisa & $\begin{array}{l}\text { Virtual lingkungan gedung } \\
\text { SMKN } 25 \text { Jakarta }\end{array}$ & $\begin{array}{l}3 \\
3 \\
3 \\
3\end{array}$ & 3 & Cukup Puas \\
\hline 2. & Dwi Alamsyah & $\begin{array}{l}\text { Virtual lingkungan gedung } \\
\text { SMKN } 25 \text { Jakarta }\end{array}$ & $\begin{array}{l}2 \\
3 \\
3 \\
4\end{array}$ & 3 & Cukup Puas \\
\hline 3. & Ivan Septiawan & $\begin{array}{l}\text { Virtual lingkungan gedung } \\
\text { SMKN } 25 \text { Jakarta }\end{array}$ & $\begin{array}{l}2 \\
4 \\
3 \\
4 \\
3\end{array}$ & 3,25 & Cukup Puas \\
\hline 4. & Eri Marwanto & $\begin{array}{l}\text { Virtual lingkungan gedung } \\
\text { SMKN } 25 \text { Jakarta }\end{array}$ & $\begin{array}{l}4 \\
3 \\
3\end{array}$ & 3,25 & Cukup Puas \\
\hline 5. & Indri Rahmawati & $\begin{array}{l}\text { Virtual lingkungan gedung } \\
\text { SMKN } 25 \text { Jakarta }\end{array}$ & $\begin{array}{l}2 \\
3 \\
3 \\
3\end{array}$ & 2,75 & Cukup Puas \\
\hline
\end{tabular}

\section{f. Hasil Perolehan Tingkat Kepuasan}

Fitur yang membantu dalam pengujian aplikasi ini yaitu umpan balik, untuk mengukur kepuasan pengguna. Berikut ini adalah perolehan tingkat kepuasan pengguna pada aplikasi pada mode virtual reality dapat dilihat pada tabel 7.

\section{g. Grafik Tingkat Kepuasan}

Hasil dari kuesioner adalah tingkat kepuasan terhadap menu aplikasi dan tingkat hasil kepuasan pada mode virtual reality yang dirasakan oleh pengguna. Nilai kepuasan pengguna bisa dilihat pada gambar grafik, dapat disimpulkan bahwa rata-rata pengguna memberikan nilai 3.4 atau cukup pada kepuasan tampilan menu utama, dan memberikan nilai 3.05 pada kepuasan mode virtual.

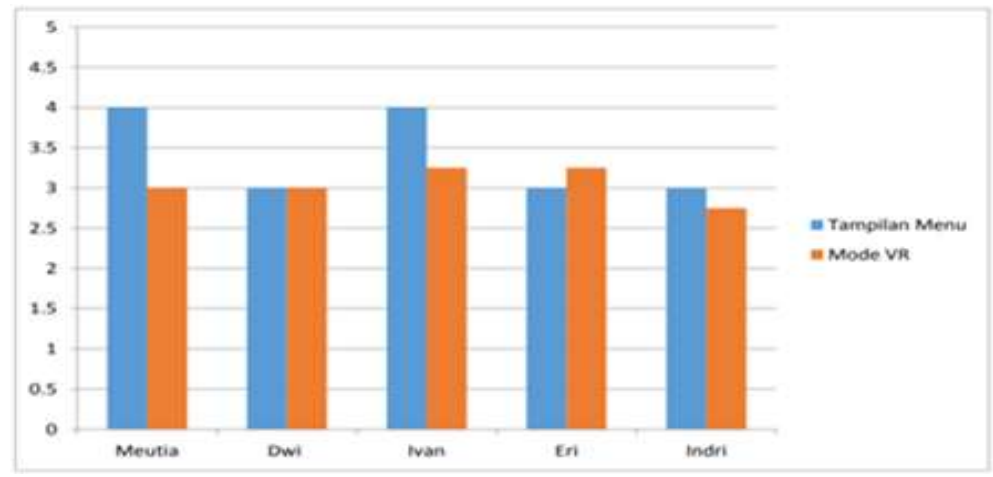

Gambar 10. Grafik tingkat kepuasan 


\section{KESIMPULAN}

Aplikasi Virtual Reality SMKN 25 Jakarta ini secara keseluruhan berdasarkan pengujian tingkat kecepatan aplikasi di smartphone tergolong lambat dikarenakn aplikasi yang tergolong berat dan banyak objek 3D, sehingga membutuhkan perangkat smartphone dengan spesifikasi yang bagus. Dengan menggunakan metode Research and Development yang membuat aplikasi dapat diselesaikan dengan baik. Tujuan Dari hasil aplikasi Virtual Reality SMKN 25 Jakarta ini dapat menghasilkan visualisasi gedung sekolah 3D SMKN 25 Jakarta yang dimana dalam visualisasi tersebut terdapat sejumlah informasi mengenai nama ruangan di sekolah tersebut baik berupa teks dan suara. Sehingga pengguna dapat mengetahui informasi mengenai ruangan - ruangan yang ada di SMKN 25 Jakarta.

\section{REFERENCES}

[1] H. Thuan et al., "Virtual Reality Technology for Campus Media Information," vol. 6, no. 1, pp. 71-76, 2019.

[2] D. Meidelfi, H. A. Mooduto, and D. Setiawan, "Visualisasi 3D Gedung dengan Konsep Virtual Reality Berbasis Android," INVOTEK J. Inov. Vokasional dan Teknol., vol. 18, no. 1, pp. 59-66, 2018.

[3] F. S. Riyadi, A. Sumarudin, and M. S. Bunga, "Aplikasi 3D Virtual Reality Sebagai Media Pengenalan Kampus Politeknik Negeri Indramayu Berbasis Mobile," JIKO (Jurnal Inform. dan Komputer), vol. 2, no. 2, p. 75, 2017.

[4] A. Kusumaningsih, C. V. Angkoso, and N. Anggraeny, "Virtual Reality Museum Sunan Drajat Lamongan Berbasis Rulebased System untuk Pembelajaran Sejarah," J. Teknol. Inf. dan Ilmu Komput., vol. 5, no. 4, p. 473, 2018.

[5] M. Bagus, W. Radityatama, G. Made, A. Sasmita, N. Kadek, and A. Wirdiani, "Aplikasi Pemodelan Gedung Rektorat Universitas Udayana Berbasis Virtual Reality,” J. Ilm. Merpati (Menara Penelit. Akad. Teknol. Informasi), vol. 7, no. 1, pp. 58-66, 2019.

[6] C. Machover and S. E. Tice, “- Virtual Reality - Virtual Reality,” IEEE Comput. Graph. Appl., vol. 6, no. January, pp. 15-16, 1997.

[7] Abdussalam, Sulthoni, and Munzil, "Media Virtual Reality Tata Surya untuk Meningkatkan Kemampuan Retensi," Pendidikan, vol. 3, no. 9, pp. 1160-1167, 2018.

[8] D. R. D. Eryanto and J. Prestiliano, "Design of learning media for the solar system lesson using animation and virtual reality,” Open Sci. J., vol. 2, no. 1, pp. 1-13, 2017.

[9] M. A. Pranata, G. S. Santyadiputra, and I. G. P. Sindu, "Rancangan Game Balinese Fruit Shooter Berbasis Virtual Reality Sebagai Media Pembelajaran,” J. Nas. Pendidik. Tek. Inform., vol. 6, no. 3, p. 256, 2018.

[10] I. M. A. Pradnyana, I. K. R. Arthana, and I. G. B. H. Sastrawan, "Pengembangan Virtual Reality Pengenalan Binatang Buas Untuk Anak Usia Dini,” Lontar Komput. J. Ilm. Teknol. Inf., vol. 6, p. 188, 2017.

[11] E. Y. Putra, A. Wahyudi, and A. Tumilaar, "Virtual Reality 360 Interactive Digital Tour of Tomohon City with Stereoscopic Views," Cogito Smart J., vol. 4, no. 1, pp. 104-112, 2018.

[12] P. Irwandi, A. Erlansari, and R. Effendi, "Perancangan Game First Person Shooter (FPS) 'Boar Hunter' Berbasis Virtual Reality," J. Rekursif, vol. 4, no. 1, pp. 68-79, 2016.

[13] J. T. Pendidikan, F. I. Pendidikan, and U. N. Malang, "Taman peninggalan sejarah berbasis virtual reality," pp. 7-12, 1975.

[14] M. Jamil, “Pemanfaatan Teknologi Virtual Reality (VR) di Perpustakaan,” J. Inform., no. 2017, pp. 99-113, 2017.

[15] Abdussalam, Sulthoni, and Munzil, "Media Virtual Reality Tata Surya untuk Meningkatkan Kemampuan Retensi," Pendidikan, vol. 3, no. 9, pp. 1160-1167, 2018.

[16] D. L. Gunawan, Liliana, and G. S. Budhi, "Pembuatan Kebun Binatang Virtual Untuk Pembelajaran Mengenai Binatang Liar," p. 6, 2016.

[17] G. A. Putra, R. Kridalukmana, and K. T. Martono, "Pembuatan Simulasi 3D Virtual Reality Berbasis Android Sebagai Alat Bantu Terapi Acrophobia," J. Teknol. dan Sist. Komput., vol. 5, no. 1, p. 29, 2017.

[18] R. Wojciechowski, K. Walczak, M. White, and W. Cellary, "Building virtual and augmented reality museum exhibitions," Web3D Symp. Proc., no. May 2014, pp. 135-144, 2004.

[19] H. Thuan et al., "Virtual Reality Technology for Campus Media Information,” vol. 6, no. 1, pp. 71-76, 2019.

[20] A. Kusumaningsih, C. V. Angkoso, and N. Anggraeny, "Virtual Reality Museum Sunan Drajat Lamongan Berbasis Rulebased System untuk Pembelajaran Sejarah,” J. Teknol. Inf. dan Ilmu Komput., vol. 5, no. 4, p. 473, 2018. 